\title{
Analysis and Risk Study on Landslide Hazard Frequency at Road Corridor of Batu City - Kediri Regency Border
}

\author{
Emil Wahyudiyanto \\ Public Works Offices Bina Marga, East Java Province, Surabaya, INDONESIA \\ emilnasbaw@gmail.com
}

\begin{abstract}
Road corridor of Kota Batu - Kediri Regency Boundary is a provincial road that has a vital function for the economic and tourism movement from and to Batu City in East Java Province. This inter-regency road is historically vulnerable to disaster events such as landslide, Kali Konto flash flood, Kelud Mountain lahar, flood inundation, etc. This research was referred to Regulation of Ministry of Public Work No.22/PRT/M/2007 on Guidelines for Spatial Planning of Landslide Vulnerable Areas and helped with Geographic Information System (GIS). Method comparison was also conducted by Meiliana (2011) with the indicators from the same regulation, and by using Landslide Hazard Assessment (LHA) method that is based on historical data. The landslide risk mapping with LHA method that is combined with analysis result from the vulnerability of moving vehicles is suggested to be the reference in mapping the mass-movement disaster risk on Indonesian road corridors. Analysis on frequency of rainfall that triggered landslide concluded that the probability of landslide occurrence (PLO) on daily rainfall was $126.2 \mathrm{~mm}$, or 3 dayscumulative rainfall of $192.26 \mathrm{~mm}$.
\end{abstract}

Keywords: road landslide, risk mapping, landslide inventory, frequency analysis

\section{BACKGROUND}

The Province of East Java has a mountainous and hilly topography that is vulnerable to landslide disaster or flash flood. The disaster events placed East Java Province on the $15^{\text {th }}$ of the 2013 Indonesia Risk Disaster Index level. The landslide disaster event record in East Java showed that there were 357 landslide events on 1998-September 2016, with the total death toll of 96 lives, 4 people missing, 291 people injured, and 3087 people were displaced (Indonesian National Board for Disaster Management, 2016). The administrative areas that became the subject of this research, Malang Regency and Batu City, were ranked $9^{\text {th }}$ on 2013 Indonesia Risk Disaster Index (Indeks Risiko Bencana Indonesia-IRBI) of entire Malang Regency, or $2^{\text {nd }}$ in the provincial level.

Landslide disaster in East Java has a negative impact for its financial and economic factor, and also gives damage to its infrastructure. The landslide event record on the road corridor of Batu City - Kediri Regency Boundary took the time span of 8 years, between 2007 up to 2016. The data interpretation result showed 92 points of landslide location with 50 days event, with the peak landslide event was between January and February $(82.61 \%)$.

Mapping and analysis of landslide disaster risk on road corridor of Batu City - Kediri Regency Boundary was an urgent matter, because the road area has a high landslide risk level in East Java Province. Selecting an appropriate method in mapping the disaster risk was very useful in understanding the landslide character of the landslide-prone segments.

Research on the characteristic of the rainfall that triggered the landslide in the area was also needed in order to increase the disaster resilience capacity of the road users and the policy stakeholder (Faris and Fathani, 2013).

\section{LANDSLIDE RISK MITIGATION}

\subsection{Hazard Map of Landslide Disaster}

Landslides, that cause environmental damage and economic losses and death are commonly triggered by rainfall (Laprade, et al., (2000); Salvati, et al., (2010)). The Regulation of Ministry of Public Work No.22/PRT/M/2007 divided the risk aspects into two categories, which are natural physical aspect and human activity aspect, with various accompanying indicators. The indicators on natural physical aspect are $30 \%$ for slope angle, $15 \%$ for soil condition, $20 \%$ for slope-forming rocks, $15 \%$ for rainfall, $7 \%$ for slope's water system, $3 \%$ for seismic factor, and $10 \%$ for vegetation. As for vulnerability level indicator on human activities are $10 \%$ for cropping pattern, $20 \%$ for slope cutting and excavation, $10 \%$ for pond, $10 \%$ for drainage, $20 \%$ for construction work, $20 \%$ for population density, and $10 \%$ for mitigation effort. 
Meiliana (2011) conducted a modification on the indicator used in the Regulation of Ministry of Public Work No.22/PRT/M/2007, with the consideration of the risk indicator that suitable to the road corridor on her research. The research indicators on Meiliana (2011) study were 6 (six) on natural physical aspect: slope angle (30\%), soil condition (15\%), slope-forming rocks $(20 \%)$, rainfall $(15 \%)$, distance from river $(7 \%)$, and vegetation $(13 \%)$. The vulnerability indicators on the human activity aspects consisted of 5 indicators as follows: cropping pattern (20\%), slope cutting or excavation $(20 \%)$, pond $(25 \%)$, population density $(15 \%)$, and mitigation effort (10\%).

Landslide risk mapping using the Regulation of Ministry of Public Work No.22/PRT/M/2007 did not conclude the historical element of past landslide events, even though historical record of landslide event could be used to conduct validation, identification, and mapping the characteristic of landslide distribution on a region.

Risk mapping on road corridor has been conducted by Yivru (2015) at the road corridor of Saint Lucia and Dominica, Northmore (2000) in Jamaica, Gaurav (2009) in Uttarakhand, and Eker (2014) in Turkey, as well as other researches. Yivru (2015) conducted a multi-criteria spatial approach sourced from historical data, which were named as Landslide Hazard Assessment (LHA).

The criteria for the indicators that were used in the method are as follows: (i) weight of the landslide data that was represented with per kilometer landslide density was $50 \%$; (ii) road slope $(25 \%$ ); (iii) road drainage (8\%); (iv) slope-forming material (17\%), which each was divided into $40 \%$ of geological element and $60 \%$ soil type. The most important weight on the risk mapping element was the landslide data which was obtained from the landslide inventory data.

The landslide inventory data is very significant in the landslide study, yet it takes a long time in the process of collecting the data (Nayak, et al., 2010). Survey on landslide inventory could be conducted by using satellite imaging or direct field-mapping. Guzzetti (2012) argued that a landslide inventory map could be used for: (i) documenting landslide phenomenon on a range of areas; (ii) initial stage of creating a hazard map; (iii) conducting investigation on distribution, movement pattern, and landslide pattern related to morphology or geological characteristic; and (iv) evolution study from a regional land use.

\subsection{Vulnerability on Moving Vehicles}

Landslide vulnerability of a road corridor for the road users has different characteristic compared with landslide vulnerability of an area for its occupants. Residents that permanently live on a landslide-prone area have a high level of exposure, while the moving vehicle that moves through a road corridor has relative exposure level based on the length of the track, the velocity of the vehicle, type of the vehicle, and the characteristic of the occurring landslide.

Study of Pierson \& van Vickle (1993) which was adopted by Guzzeti (2005), Liu (2006), Gaurav (2009), Nayak (2010), Iswar (2010), Nugroho (2012), Eker (2014) was a detailed research that discussed about the vulnerability of vehicle movement to landslide and debris hazard. Nicolet (2016) compared methods, which resulted to the conclusion that vehicle speed, vehicle distribution, vehicle dimension, velocity, landslide dimension, and track length are main elements in calculating the vehicle vulnerability

Vehicle type basically contributes to the vulnerability of the passenger. For example, the risk of victim caused by a landslide on motorcycle driver is certainly greater than a passenger in a large bus. Buwal (1999) created a method of passenger number estimation related to rock fall, by considering the lethal rate of vehicle type (Prina, et al., 2004).

\subsection{Risk Analysis on Landslide-Triggering Rainfall}

In general, researches agree that trigger rainfall event is a period of continuous or almost continuous rain, starts from a rain event or sudden intensity increase of a mild rain period, which then ended when the landslide occurred (Berti, 2012; Faris and Fathani, 2013; Faris and Wang, 2014).

Berti (2012) stated that the greatest uncertainty in determining threshold of the rainfall that trigger landslide lies on the determining the initial point of the trigger rain. Aleotti (2004) chose visual approach, while Frattini et al. (2009) used a lot of time frames in determining the initial point of the determinant rain.

Chleborad et al. (2006) suggested a prediction for trigger rain that causes landslide based on the cumulative rainfall threshold (CT) 3 days before the event $\left(P_{3}\right)$ with 15 days of rain before the $P_{3}$ that is known as $P_{15}$. From the study on 577 landslide events in Seattle on year of 1978 to 2003, Chleborad et al. (2006) created a correlation between $P_{3}$ and $P_{15}$ that is known as the lower-bound threshold of the landslidetriggering cumulative rainfall.

Huang (2015) conducted a different approach in research at Huangshan, China. Huang (2015) determined the lower-bound threshold of landslidetriggering rainfall through linear regression approach on the lowest points that represent landslide events 
caused by rain. The abscissa axis is the cumulative rainfall $R_{t}$ (in millimeter) which is defined as cumulative rainfall for 7 days, while ordinate axis is $I_{h}$, rainfall intensity in $\mathrm{mm} /$ hour unit.

Huang (2015) determined $P L O=10 \%$ for lower-bound threshold and $P L O=90 \%$ for the upper-bound threshold. The algorithm in the straight line equation follows Equation 1 as follows:

$R_{t}+\alpha \cdot I h=C$

In which $R t$ is cumulative rainfall $(\mathrm{mm}), I h=$ hourly rainfall intensity $(\mathrm{mm} / \mathrm{hr})$, and $C=$ numeric constant

Equation 1 resulted into two $C$ values, which are $C_{\min }$, and $C_{\max }$ that each is constant value for lower-bound threshold line and upper-bound threshold line. Relation between $C$ value and PLO was then followed by Equation 2.

$\frac{C-C_{\min }}{C_{\max }-C_{\min }}=\left(\frac{P L O-0}{1-0}\right)^{2}=P L O^{2}$

By using the Equation 2, the landslide probability for each point that is located between lower-bound threshold and upper-bound threshold could be known. Huang (2015) used short-period rainfall data with certain PLO value span to determine the hazard level classification. However, hourly rainfall data was not available at the research field, therefore making it not possible to create warning status that is based on shortperiod rainfall data.

\section{RESEARCH METHOD}

This research compared 3 (three) risk mapping methods, which are: (i) Regulation of Ministry of Public Work No.22/PRT/M/2007; (ii) Regulation of Ministry of Public Work No.22/PRT/M/2007 that was modified by Meiliana (2011); and (iii) LHA method \& calculation on the vulnerability of moving vehicle. Further process in the research was to analyze landslide-triggering rainfall frequency based on landslide event record between year 2007 and 2016.

Regulation of Ministry of Public Work No.22/PRT/M/2007 divides hydrogeomorphology condition of an area into 3 (three) zone typologies. The typologies are then divided based on the height span of an area:

a. Zone with high level of landslide potential if the weight value total of the measured aspect is on range of $2.40-3.00$

b. Zone with medium level of landslide potential if the weight value total of the measured aspect is on range of $1.70-2.39$ c. Zone with low level of landslide potential if the weight value total of the measured aspect is on range of $1.00-1.69$.

The assessment on the vulnerability level of entire aspects was next conducted by averaging the measured weight value on the natural physical aspects with the measured weight value on the human activity aspects. The entire of weighting classes is shown in Table 1 and Table 2 of the Regulation of Ministry of Public Work No.22/PRT/M/2007 on the criteria and indicator of vulnerability level for zone with landslide potential type A, B, and C.

The result from Meiliana (2011) and original method from the regulation then was compared with LHA method which has been specifically applied as mapping method on a road corridor that based with historical data. The record of landslide event on the researched road corridor was on the time span of 8 years, between 2007 up to 2016. The data was obtained from the record of Office of Public Works and Highways of East Java Province, Regional Disaster Management Agency, and verified online media. Total recorded event was 92 event points with total days of 50 days. This data then would be correlated with rainfall that triggered landslide, in order to obtain threshold of the rainfall that triggered landslide as conducted by Vennari (2014).

\section{RESEARCH RESULT}

\subsection{Geo-hydro morphology of Research Area}

The analysis result from the slope vulnerability division was as shown in Table 1 . The type $B$ landslideprone geo-hydro morphology area is located in the road segment between Km 19+500-53+000 (P26), while type $\mathrm{C}$ landslide-prone area is located on road segment of Km 53+000(P26)-63+890 (P36+890).

Table 1. Division of Hydrogeomorphology Classification

\begin{tabular}{llll}
\hline Hydrogeomorphology & $\begin{array}{l}L \\
(\mathrm{~km})\end{array}$ & $\begin{array}{l}\text { Elevation }(\mathrm{m} \\
\mathrm{asl})\end{array}$ & $\%$ \\
\hline $\begin{array}{l}\text { Type B Landslide- } \\
\text { prone }\end{array}$ & 33.50 & $500-1183$ & 75.4 \\
$\begin{array}{l}\text { Type C Landslide- } \\
\text { prone }\end{array}$ & 10.89 & $196-500$ & $\begin{array}{l}7 \\
24.5 \\
\text { Total }\end{array}$ \\
\hline
\end{tabular}

\subsection{Natural Aspect}

Indicators that were considered in the calculation of natural physical aspects are as follows.

\subsubsection{Slope Angle}

Slope angle in this research was the slope gradient that was resulted from survey of landslide inventory. The slope degree was gained by averaging right and left 
side of the gradient degree, by considering the nature of landslide threat on the road which does not always come from upper side (cliff side), but could also come from slope side of the road (lower side). Classification of the vulnerability of slope angle indicator is shown in Table 2. The recapitulation of vulnerability of slope angle indicator on the studied road corridor is shown in Table 3.

Table 2. Hydrogeomorphology of Type B and Type C Landslide-prone

\begin{tabular}{llll}
\hline Sensitivity & $\begin{array}{l}\text { Type B } \\
\text { gradient }\end{array}$ & $\begin{array}{l}\text { Type C } \\
\text { gradient }\end{array}$ & Weight \\
\hline High & $35 \%-40 \%$ & $15 \%-20 \%$ & 3 \\
\hline Medium & $30 \%-<35 \%$ & $8 \%-<15 \%$ & 2 \\
\hline Low & $21 \%-<30 \%$ & $0 \%-<8 \%$ & 1 \\
\hline
\end{tabular}

Table 3. Recapitulation of the Vulnerability off Slope Angle Indicator

\begin{tabular}{lllll}
\hline No & Vulnerability class & $L(\mathbf{k m})$ & Value & $\%$ \\
\hline 1 & High & 24.80 & 3 & 55.86 \\
2 & Medium & 0 & 2 & 0 \\
3 & Low & 6.44 & 1 & 14.51 \\
4 & Very Low & 13.15 & 0 & 29.63 \\
\hline & Total & 44.39 & & 100 \\
\hline
\end{tabular}

\subsubsection{Soil Type}

The condition of surface soil that was passed by the studied road corridor consisted of various type of soils, granular soil, cohesive soil, and cobbles. From the map owned by related institution, data of the road trace based on the soil type is shown in Table 4 .

Another method that is better in determining the sensitivity of soil type to landslide is by conducting soil type test through taking sample on the field. However, this method was difficult to be conducted in this research, due to the high number of test sample needed (time limit).

Table 4. Recapitulation of Soil Type Indicator Vulnerability

\begin{tabular}{|c|c|c|c|c|}
\hline No & Soil type & $L(\mathrm{~km})$ & $\%$ & Value \\
\hline 1 & Inceptisol & 3.90 & 8.79 & 5 \\
\hline 2 & Mollisol & 0.20 & 0.45 & 5 \\
\hline \multirow[t]{2}{*}{3} & Brown and & & & \\
\hline & $\begin{array}{l}\text { Yellowish Brown } \\
\text { Complex Andosol, \& } \\
\text { Litosol }\end{array}$ & 12.10 & 27.26 & 4 \\
\hline \multirow[t]{2}{*}{4} & Association of Grey & & & \\
\hline & $\begin{array}{l}\text { \& Greyish Brown } \\
\text { Alluvial }\end{array}$ & 5.80 & 13.07 & 1 \\
\hline 5 & $\begin{array}{l}\text { Association of } \\
\text { Brown Andosol, Glei } \\
\text { Humus }\end{array}$ & 7.30 & 16.45 & 4 \\
\hline \multirow[t]{2}{*}{6} & $\begin{array}{l}\text { Complex Regosol } \\
\text { and Litosol }\end{array}$ & 15.09 & 33.99 & 5 \\
\hline & Total & 44.39 & 100.00 & \\
\hline
\end{tabular}

\subsubsection{Geology}

The geology map of the research area that was obtained from related institution has accuracy degree limited to the rock formation distribution. The analysis result showed data on the road trace at research area, which passed the rock formation of Old Anjasmara Mountain (Qpat) of 30,1 km length (68\%), between Km 19+50049+600. The rest, which was $\mathrm{Km} \mathrm{46+600} \mathrm{-} \mathrm{63+890,}$ passed through the rock formation of Young Anjasmara Mountain (Qpva) of $14.29 \mathrm{~km}$ length $(32 \%)$. Because there was no detailed data on the bedrock distribution, the indicator assessment then took three maximum values. This is based on the description of high vulnerability indicator value on bedrock in Regulation of Ministry of Public Work No.22/PRT/M/2007, i.e. slope that is arranged with rocks and has many crack structures.

\subsubsection{Rainfall}

The Regulation of Ministry of Public Work No.22/PRT/M/2007 put weight value on landslide susceptibility caused by rainfall indicator, which is: (i) vulnerability value 3 (three)/high for yearly rainfall that is more than $2500 \mathrm{~mm} / \mathrm{year}$; (ii) value of 2 (two)/medium for yearly rainfall value between 1000 $2500 \mathrm{~mm} / \mathrm{year}$; and (iii) value of 1 (one)/low for mean yearly rainfall value less than $1000 \mathrm{~mm} / \mathrm{year}$. Road segmentation based on vulnerability value caused by rainfall is as shown in Table 5 as follows.

Table 5. Rain station that were affecting the analysis

\begin{tabular}{llll}
\hline Rain Station & $L(\mathrm{~km})$ & Rainfall $(\mathrm{mm} /$ year $)$ & Value \\
\hline Ngaglik & 4.20 & 1788.75 & 2 \\
Pujon & 6.90 & 2617.28 & 3 \\
Kedungrejo & 6.40 & 2487.34 & 2 \\
Ngantang & 10.20 & 4238.75 & 3 \\
Jombok & 8.80 & 3046.76 & 3 \\
Kasembon & 7.89 & 2330.82 & 2 \\
\hline Total & 44.39 & & \\
\hline
\end{tabular}

\subsubsection{Slope's Water System}

Regulation of Ministry of Public Work No.22/PRT/M/2007 assessed slope's water system indicator based on the sighting of water or water source on the slope, particularly on the contact area between impermeable rocks with a more permeable soil layer. The observation on the studied road corridor related to slope's water system (primary survey on April $4^{\text {th }}$ 2017) resulted on data which showed that the slopes do not have adequate slope drainage in order to quickly lower the water table at the event of rain. The rainwater that infiltrated into the soil in the hill eventually flowed through the crevices of rock discontinuity or between the soil layer and rocks. In the research of slope's water system indicator weight, its maximum weight to landslide susceptibility is of 3 (three). 


\subsubsection{Seismic Factor}

On the Regulation of Ministry of Public Work No.22/PRT/M/2007, seismic indicator is measured based on frequency of an earthquake event on a certain time span. The weight of the indicator is 3 (three) for earthquake-prone area, value of 2 (two) for area with moderate frequency of earthquake, or 1-2 times in a year; and value of 1 (one) for area with event frequency under 1 (one) time in a year.

According to seismic record in 2016 up to 2017, there were 11 (eleven) earthquake events occurred in the surrounding Malang Raya area (Malang Regency, Batu City, Malang City); with intensity above 4.9 magnitude scale (USGS, 2017); therefore the area could be classified as an earthquake-prone area (seismic indicator value of 3 ).

\subsubsection{Vegetation Type/Land Cover}

Data collecting of vegetation type on the studied road corridor was conducted simultaneously with the landslide inventory survey on December $16^{\text {th }} 2016$ and February $8^{\text {th }} 2017$.

Table 6. Roadside vegetation type

\begin{tabular}{lllll}
\hline No & Vegetation type & $L(\mathrm{~m})$ & $\%$ & Weight \\
\hline 1 & Heterogenic Forest & 8,100 & 18.25 & 1 \\
2 & Field & 6,600 & 4.51 & 3 \\
3 & Plantation & 3,300 & 7.43 & 3 \\
4 & Riverside vegetation & 2,600 & 5.86 & 3 \\
5 & Pine & 1,800 & 4.05 & 2 \\
6 & Paddy field & 1,100 & 2.48 & 3 \\
7 & Shrubs & 500 & 1.13 & 3 \\
\hline
\end{tabular}

As shown in Table 6 and Table 7, the data were quite detailed in depicting the actual condition of the existing land use. Several landslide research often use vegetation data based on the interpretation of land cover map or land use map that are obtained from related institution. However in this research, both the land use map and the land cover map did not reflect the actual vegetation condition.

If protected forest area on between $\mathrm{Km} 20+500$ $23+500$ uses vegetation interpretation based on land use, the vulnerability vegetation value is 1 (one) or in low tendency, because it is a forest area. However from the result of primary survey, the data obtained was that vegetation that dominates the area are pine trees that are categorized as vegetation with moderate level of vulnerability or value of 2 (two) (Regulation of Ministry of Public Work No.22/PRT/M/2007).

\subsubsection{Distance from River}

About $4.9 \mathrm{~km}$ on the left side of the road of Batu CityKediri Regency Boundary is directly coincided with the flow of Konto River with span of $<10 \mathrm{~m}$, while the right side of the road coincides with the river along 2.6 $\mathrm{km}$ of length. Recorded event of disaster on January $13^{\text {th }} 2010$ has collapse the main bridge, which is Ngeprih Bridge on Km 36+300 (P9+300) which caused traffic lost. Another assessment was also conducted on the stream which cut road trace by giving vulnerability weight of 3 (three).

Table 7. Recapitulation of road distance to river

\begin{tabular}{lllll}
\hline No & $\begin{array}{l}\text { Distance of road } \\
\text { centerline to river, } \mathrm{j}\end{array}$ & $L(\mathrm{~m})$ & $\%$ & Value \\
\hline 1 & $\mathrm{j}<25 \mathrm{~m}$ & 4,900 & 11.04 & 3 \\
2 & $25 \mathrm{~m}<\mathrm{j}<50 \mathrm{~m}$ & 3,600 & 8.11 & 2 \\
3 & $50 \mathrm{~m}<\mathrm{j}<100 \mathrm{~m}$ & 8,200 & 18.47 & 1 \\
4 & $\mathrm{j}>100 \mathrm{~m}$ & 27,690 & 62.38 & 0 \\
\hline & Total & 44,390 & 100 & \\
\hline
\end{tabular}

\subsection{Human Activity Aspect}

Main factors that always cause landslide risk are natural factor, human activity factor, or combination of both which further aggravate the landslide disaster event (Highland \& Bobrowsky, 2008). Both flood disaster and landslide event geographically have close relationship with human activity (Baioni, 2011). According to Regulation of Ministry of Public Work No.22/PRT/M/2007, risk mapping that involves human activity element consists of 7 (seven) indicators as follows.

\subsubsection{Cropping Pattern}

The Regulation of Ministry of Public Work No.22/PRT/M/2007 identified the landslide susceptibility caused by cropping pattern through 2 (two) approaches, the approach on vegetation type suitability of the land, and approach on cropping pattern method or season. The interpretation on the vulnerability is shown in Table 8 .

Table 8 . Vulnerability value on cropping pattern indicator

\begin{tabular}{clccc}
\hline No & $\begin{array}{c}\text { Vulnerability type } \\
\text { of cropping pattern }\end{array}$ & $L(\mathrm{~m})$ & $\%$ & Weight \\
\hline 1 & Heterogenic Forest & 8,100 & 18.25 & 1 \\
2 & Field & 6,600 & 4.51 & 3 \\
3 & Plantation & 3,300 & 7.43 & 3 \\
4 & Pines & 1,800 & 4.05 & 2 \\
5 & Paddy Field & 1,100 & 2.48 & 3 \\
6 & Shrub & 500 & 1.13 & 3 \\
\hline
\end{tabular}

\subsubsection{Slope Cutting/Excavation}

The primary survey on landslide inventory in December $16^{\text {th }} 2016$ concluded that the slope collapse events are mostly located at the slope cutting area. The angle of the slope cutting is considered to be fulfilling the technical requirements inadequately, therefore the 
slope collapse event keeps occurring. This conclusion is in line with the identification of landslide points that was conducted by Purnomo (2010). From the 34 identified points, $64 \%$ of them are located in the roadside. Identification on the field of studied road corridor showed that for $17.30 \mathrm{~km}$ or $37.8 \%$ of the road segment are slope cutting area that was caused by road construction (angle $>45^{\circ}$ ). From the assessment on the slope cutting indicator, the slope cutting road segment then was given value of 3 (three)/high vulnerability category.

\subsubsection{Pond/Paddy Field}

From the landslide inventory survey, there was no pond or paddy field to be found in the upper cliff side of the road corridor. However, the position of pond or paddy field on the studied road corridor was identified to be 800 meter of length (1.8\%). The indicator of pond/paddy field forming of the road segment then was given weight of 3 (three).

\subsubsection{Drainage}

Drainage data on the road corridor was obtained from field survey. The road drainage on the road corridor is divided into 4 (four) categories, which are: (i) drainage with concrete layer or subsurface drainage with value of 1 (one); (ii) stone masonry drainage with value of 2 (two); (iii) soil drainage with value of 3 (three); and (iv) no drainage with vulnerability value of 4 (four). Recapitulation of the existing drainage condition on the studied road corridor is shown in Table 9.

Table 9. Vulnerability value of drainage indicator

\begin{tabular}{llll}
\hline Drainage type & $L(\mathrm{~m})$ & $\%$ & Weight \\
\hline Concrete/subsurface & 200 & 0.45 & 1 \\
Stone masonry & 2,700 & 6.08 & 2 \\
Soil & 16,200 & 36.49 & 3 \\
No drainage & 25,290 & 56.97 & 4 \\
\hline Total & 44,390 & 100 & \\
\hline
\end{tabular}

\subsubsection{Construction Work}

In this research, construction work as an indicator was interpreted as settlement building or semi-permanent building that was located along the studied road corridor. The score of the construction work indicator was interpreted from the description in the Regulation of Ministry of Public Work No.22/PRT/M/2007, which is of low value or 1 (one). Location of the built construction along the studied road corridor was interpreted from the location of the settlement area land use, which was 19890 meter (44.81\%) from total length of the road corridor.

\subsubsection{Population Density}

In this research, classification of vulnerability value of the population density followed sub-district administrative level. The description on the Regulation of Ministry of Public Work No.22/PRT/M/2007 put the highest limit of vulnerability level on the population density is > 50 people/ha; medium level of vulnerability is $20-50$ people/ha; low level of vulnerability $<20$ people/ha.

\subsubsection{Mitigation}

The method on scoring the mitigation indicator in this research was by giving risk value of 0 (zero) on the road segment that has structural counter measurement, and risk value of 3 (three) on the road segment that does not have structural counter measurement.

\subsection{Risk Analysis Result}

There was difference on the risk score between the method from Regulation of Ministry of Public Work No.22/PRT/M/2007 and the method from Regulation of Ministry of Public Work No.22/PRT/M/2007 that has been modified by Meiliana (2011). Due to the removal of seismic factor indicator and slope's water system indicator, risk mapping method by modified Regulation of Ministry of Public Work No.22/PRT/M/2007 (Meiliana, 2011) gave a lower risk score result on its natural physical aspect (Table 13 and Table 14).

As for the landslide risk based on human activity aspect, the risk score resulted from method from Regulation of Ministry of Public Work No.22/PRT/M/2007 and the modified Regulation of Ministry of Public Work No.22/PRT/M/2007 by Meiliana (2011) gave an identical risk map. However, due to removal of construction work and drainage as indicators, the risk score result from the modified method by Meiliana (2011) gave higher risk score. This was because by removing those indicators, the percentage of the remaining indicators was increased (Table 13 and Table 14). From the assessment of risk mapping result from the abovementioned methods (Figure 3 and Figure 4), the resulted risk score did not depict landslide event based on historical record or landslide inventory mapping.

\subsection{Landslide Hazard Assessment (LHA) Method}

From the aforementioned risk scoring study, initial conclusion was that the Regulation of Ministry of Public Work No.22/PRT/M/2007 does not suitable to be used for mapping landslide risk of road with lengthwise typical (wide-scale mapping). A more appropriate approach would be landslide hazard assessment through spatial based multi-criteria evaluation. Yivru (2015) conducted the approach with criteria: (i) landslide density per kilometer with $50 \%$ weight; (ii) road slope (25\%); (iii) road drainage (8\%); 
(iv) slope-forming material (17\%); which each was divided by $40 \%$ of geological material and $60 \%$ of soil.

\subsubsection{Landslide density}

Landslide density is the segmentation effort from landslide distribution based on total event divided by certain units. Landslide density in this indicator was the result from analysis of landslide inventory survey on Table 1, in which then yields the landslide density value as shown in Table 10.

Table 10. Landslide density on road corridor

\begin{tabular}{llllll}
\hline $\begin{array}{l}\text { Road } \\
\text { segment }\end{array}$ & $\begin{array}{l}\text { Initial } \\
\mathrm{km}\end{array}$ & End km & $\begin{array}{l}L \\
(\mathrm{~km})\end{array}$ & $\mathrm{n}$ & $\mathrm{n} / \mathrm{km}$ \\
\hline Segment 1 & $20+400$ & $24+100$ & 3.7 & 37 & 10.00 \\
Segment 2 & $24+100$ & $29+400$ & 5.3 & 0 & 0.00 \\
Segment 3 & $29+400$ & $42+000$ & 12.6 & 66 & 5.24 \\
Segment 4 & $42+000$ & $48+000$ & 6.0 & 8 & 1.33 \\
Segment 5 & $48+000$ & $59+000$ & 11.0 & 40 & 3.64 \\
Segment 6 & $59+000$ & $63+890$ & 4.89 & 0 & 0.00 \\
\hline
\end{tabular}

\subsubsection{Slope Angle Indicator in LHA}

Slope angle indicator in this research followed research from Yivru (2015). Slope angle classification is as shown in Table 11.

Table 11. Slope angle classification in LHA Method

\begin{tabular}{lllll}
\hline No & Gradient $\left(^{(}\right)$ & $L(\mathrm{~m})$ & $\%$ & Value \\
\hline 1 & $0-5$ & 17,390 & 39.18 & 0.50 \\
2 & $5-10$ & 2,100 & 4.73 & 1.00 \\
3 & $10-20$ & 100 & 0.23 & 1.5 \\
4 & $20-30$ & 4,400 & 9.91 & 2.00 \\
5 & $30-45$ & 4,900 & 11.04 & 2.5 \\
6 & $>45$ & 15,500 & 34.92 & 3.00 \\
\hline & Total & 44,390 & 100 & \\
\hline
\end{tabular}

\subsubsection{Other Indicators in LHA}

Slope-forming material indicator in LHA method used classification as shown in Table 4. As for road drainage in this method follows classification in Table 10.

\subsubsection{Result of Landslide Hazard Assessment based on LHA Method}

Analysis on weighting of indicators in LHA method generated an identical result of vulnerability distribution with the analysis result of landslide risk that used method from Regulation of Ministry of Public Work No.22/PRT/M/2007. Recapitulation from the LHA method is as shown in Table 12. While the LA map is shown in Figure 5.
Table 12. Classification of mapping hazard with LHA method

\begin{tabular}{llll}
\hline No & Threat level & $L(\mathrm{~m})$ & $\%$ \\
\hline 1 & Very Low & 0 & 0.00 \\
2 & Low & 8,490 & 19.13 \\
3 & Moderate & 9,400 & 21.18 \\
4 & High & 8,100 & 18.25 \\
5 & Very High & 18,400 & 41.45 \\
\hline & Total & 44,390 & 100.00 \\
\hline
\end{tabular}

Data in Table 12 shows that road risk mapping with LHA method produced a more detailed score span compared with method from Regulation of Ministry of Public Work No.22/PRT/M/2007. Factors of uncertainty such as river distance, vegetation, cropping pattern, slope cutting, and land use, were in fact also calculated into the analysis through the historical record data of landslide event.

\subsection{Threshold of Landslide-Triggering Rainfall}

According to the research of Chleborad et al. (2006) and Huang (2015), determination of the landslidetriggering rainfall was applied on the road corridor of Batu City-Kediri Regency Boundary. Both of the methods could not be applied entirely because of the limited data of the short period rain distribution in the research field. The drawing of lower-bound threshold of the landslide-triggering rainfall in this research followed the method of Huang (2015), which was by pulling regression from lowest points of the rainfall data which was considered to be representative; this is as shown in Figure 1, in which then would create linear equation that followed Equation 2. Further then, the line of PLO 90\% was created by leaving 3 (three) rain events that were considered not a trigger for landslide. This was considered to be quite representative, since the total of sample data that was used in this analysis was 3324 days, whereas the total of PLO 90\% events that were exceeded was well below $1 \%$. Figure 2 shows the threshold of landslide-triggering rainfall correlation of $\mathrm{P}_{0}$ and $\mathrm{P}_{7}$.

As for the analysis on landslide-triggering rainfall that was described by Huang (2015), result of frequency analysis generated lower-bound threshold value equation (Probability of Landslide Occurrence, PLO $10 \%) \quad P_{0}=-0,2524 P_{7}+14,238$, and upperbound equation (PLO 90\%) $P_{0}=-0.2524 P_{7}+$ 126.2. Probability of landslide event was close to $90 \%$ on daily rainfall of $126.2 \mathrm{~mm}$. 


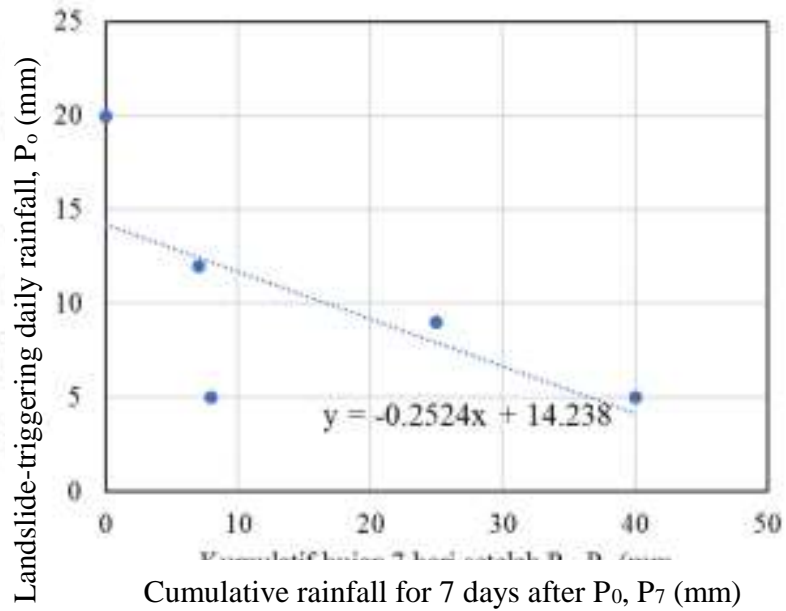

Figure 1. The withdrawing of lower-bound threshold gradient of landslide-triggering rainfall (PLO 10\%).

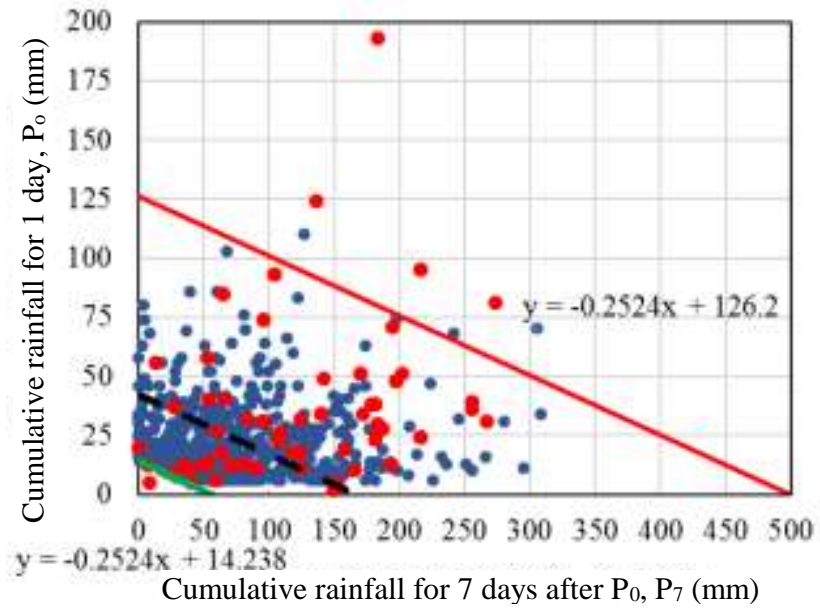

- Non-occurrence rainfall

- Landslide occurrence rainfall

L Linear (Lower bound threshold)

L Linear (Upper bound threshold)

Figure 2. Threshold of landslide-triggering rainfall correlation of $\mathrm{P}_{0}$ and $\mathrm{P}_{7}$.

Table 13. Result recapitulation of the landslide disaster risk mapping with method from Regulation of Ministry of Public Work No.22/PRT/M/2007

\begin{tabular}{lllrrrrr}
\hline \multirow{2}{*}{ No } & \multirow{2}{*}{ Risk level } & \multicolumn{2}{c}{ Natural aspect } & \multicolumn{2}{c}{ Human activity aspect } & \multicolumn{2}{c}{ Last risk } \\
\cline { 3 - 7 } & & Length $(\mathrm{m})$ & $\%$ & Length $(\mathrm{m})$ & $\%$ & Length $(\mathrm{m})$ & $\%$ \\
\hline 1 & High & 24,300 & 54.74 & 0.00 & 0.00 & 400 & 0.90 \\
2 & Medium & 8,890 & 20.03 & 12,600 & 28.38 & 21,100 & 47.53 \\
3 & Low & 11,200 & 25.23 & 31,790 & 71.62 & 22,890 & 51.57 \\
\hline & Total & 44,390 & 100.00 & 44,390 & 100.00 & 44,390 & 100.00 \\
\hline
\end{tabular}

Table 14. Result recapitulation of the landslide disaster risk mapping with method from modified Regulation of Ministry of Public Work No.22/PRT/M/2007 (Meiliana, 2011)

\begin{tabular}{lllrlrcc}
\hline \multirow{2}{*}{ No } & \multirow{2}{*}{ Risk level } & \multicolumn{2}{c}{ Natural aspect } & \multicolumn{2}{c}{ Human activity aspect } & \multicolumn{2}{c}{ Risk } \\
\cline { 3 - 7 } & & Length $(\mathrm{m})$ & $\%$ & Length $(\mathrm{m})$ & $\%$ & Length $(\mathrm{m})$ & \multicolumn{2}{c}{$\%$} \\
\hline 1 & High & 20,300 & 45.73 & 1,000 & 2.25 & 2,000 & 4.51 \\
2 & Medium & 8,100 & 18.25 & 11,700 & 26.36 & 17,400 & 39.20 \\
3 & Low & 15,990 & 36.02 & 31,690 & 71.39 & 24,990 & 56.30 \\
\hline & Total & 44,390 & 100.00 & 44,390 & 100.00 & 44,390 & 100.00 \\
\hline
\end{tabular}




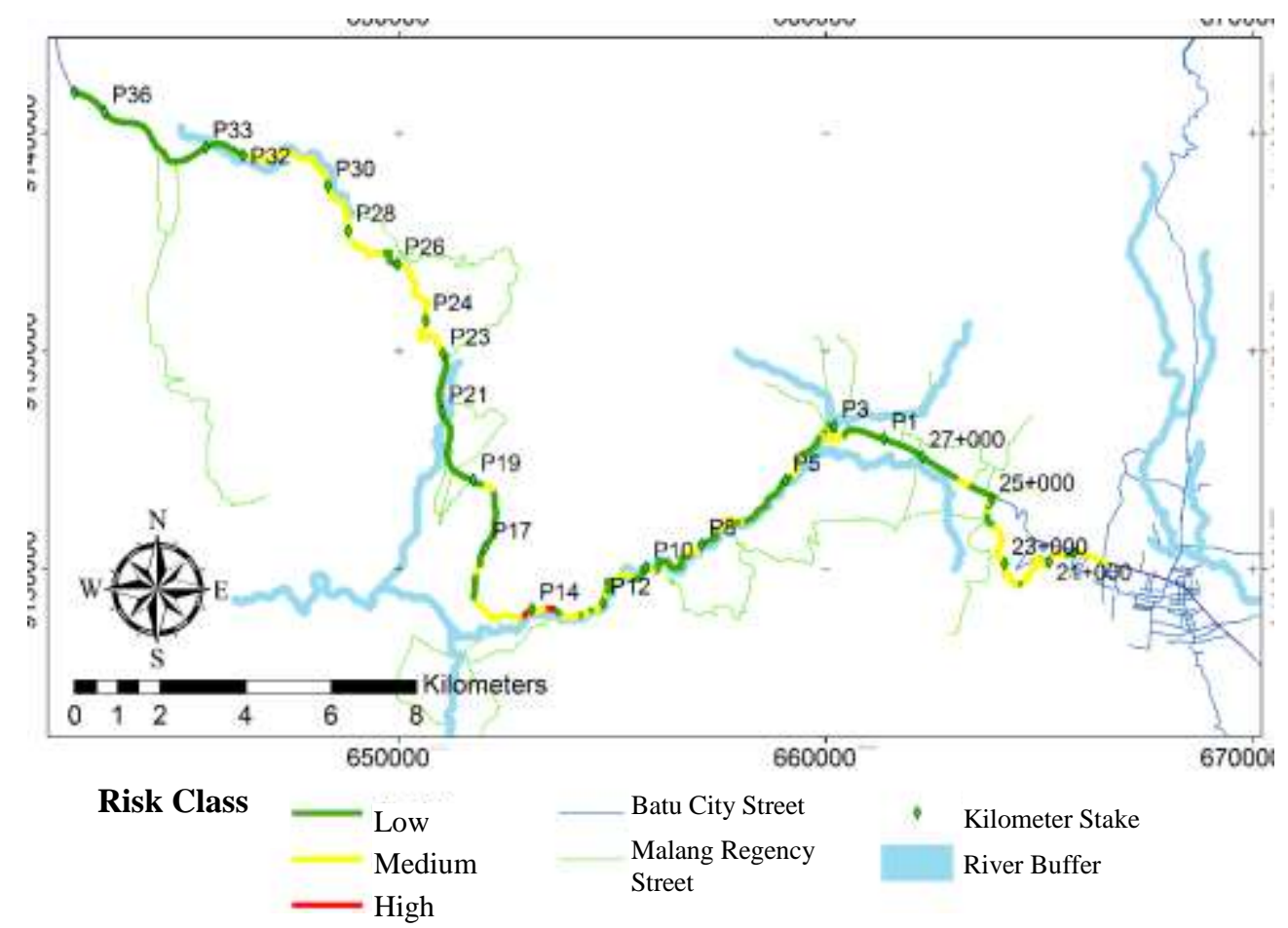

Figure 3. Landslide risk map with Regulation of Ministry of Public Work No.22/PRT/M/2007.

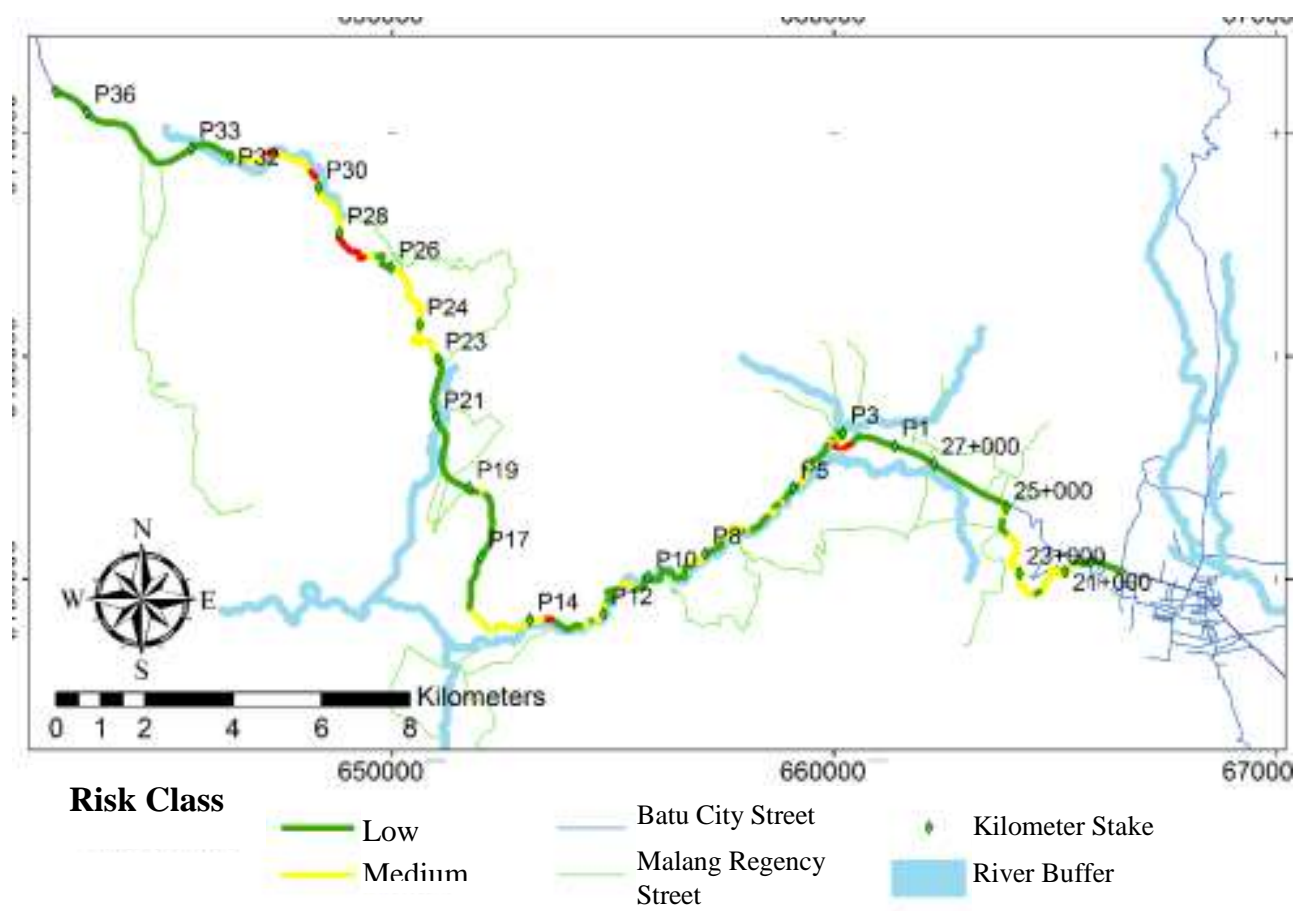

Figure 4. Landslide risk map with Regulation of Ministry of Public Work No.22/PRT/M/2007 modified by Meiliana (2011). 


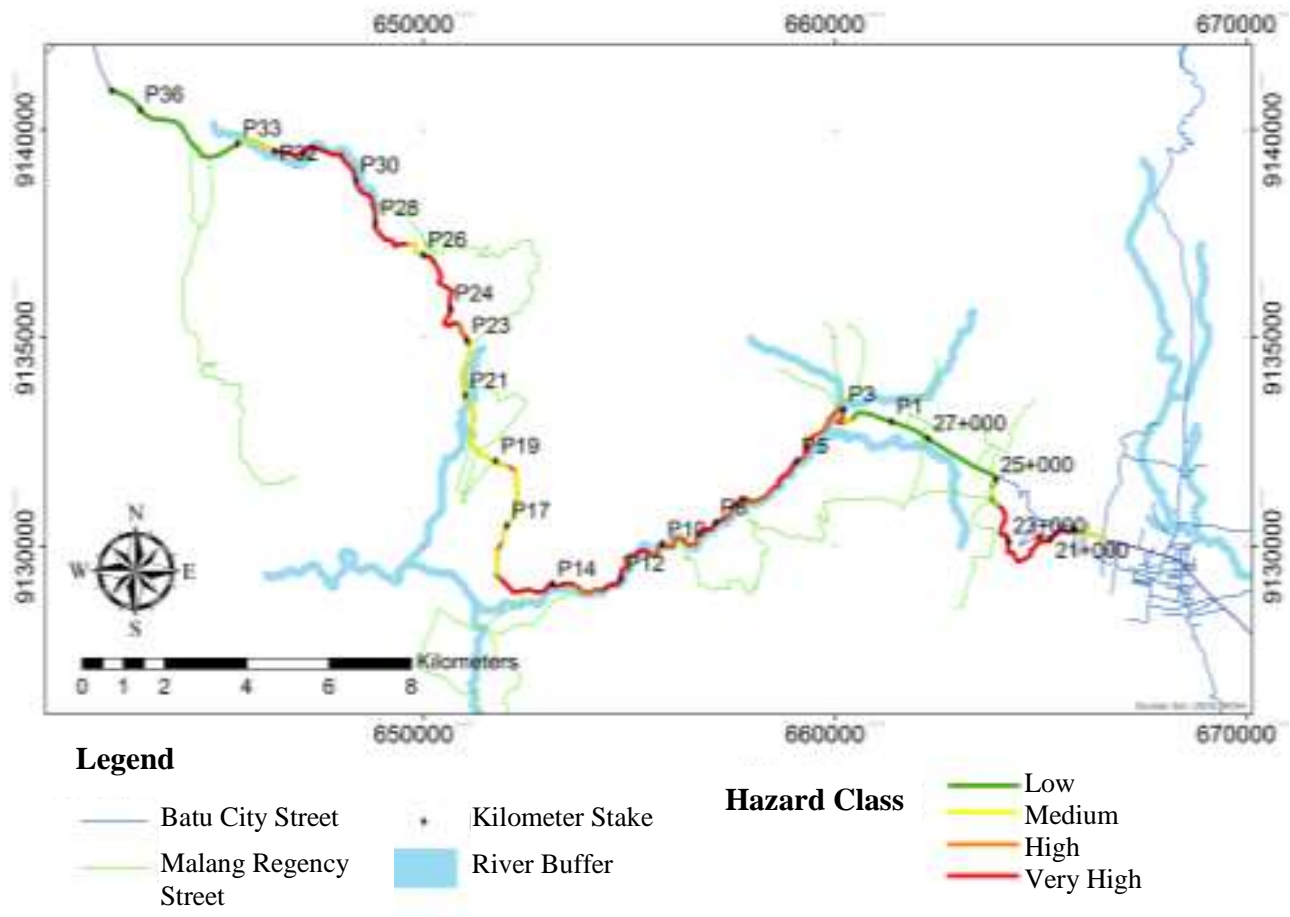

Figure 5. Landslide Hazard Assessment (LHA) map.

\section{CONCLUSION}

Risk mapping with method from Regulation of Ministry of Public Work No.22/PRT/M/2007 is more appropriate to be used in a region that does not have adequate record of landslide event. However, if the record of landslide event is available, historical databased mapping would result risk value that is close to reality.

Landslide risk mapping on a road corridor would be more detailed and close to reality if it is conducted with LHA method that is combined with assessment on vehicle movement vulnerability. Historical record of landslide event on a road corridor could be used to assess financial risk on road users, including the probability of the event occurrence on certain time.

On the studied road corridor, the probability of landslide event was close to $90 \%$ on daily rainfall of $126.2 \mathrm{~mm}$. The availability of gauge station for short period rainfall on landslide-prone road corridor is urgently required. This is intended to reduce landslide disaster risk through capacity building, development of early-warning system, and improving the safety of the road users.

\section{ACKNOWLEDGMENT}

Appreciation is submitted to the Office of Public Works and Highways of East Java Province, Water Resources Office of East Java Province, Local Government of Batu City, and Local Government of Malang Regency, particularly the Regional Disaster
Management Agency, Water Resources Office, and the Development Planning Agency at Sub-National Level for the help and support for this research data.

\section{REFERENCES}

AGS, 2000. Landslide Risk Management Concepts and Guidelines, Sydney: Australian Geomechanics Society: Sub Committee on Landslide Risk Management.

Aleotti, P., 2004. A warning system for rainfallinduced shallow failures. Engineering Geology, Volume 73, pp. 247-265.

Baioni, D., 2011. Human activity and damaging landslides and floods on Madeira Island. Natural Hazards Earth System Science, Volume 11, p. 3045.

Berti, M. et al., 2012. Probabilistic rainfall thresholds for landslide occurrence using a Bayesian approach. Journal of Geophysical Research, 117(F04006), pp. 111.

BUWAL, 1999. Vulnerability and Risk Assessment of Mountain Road Crossing Landslide. Rivista Italiana in Geotecnica, 2(April), p. 76.

Chleborad, A. F., Baum, R. L. \& Godt, J. W., 2006. Rainfall Threshold for Forecasting Landslide in Seattle, Washington, Area-Exceedance and Probability, Virginia: U.S. Geological Survey OpenFile Report 2006. 
Department of Public Work, 2007. Guideline for Landslide Spatial Planning No.22/PRT/M/2007, Jakarta: Directorate General of Spatial Planning of Department of Public Work.

Eker, R. \& Aydin, A., 2014. Assessment of forest road conditions in terms of landslide susceptibility: a case study in Yiğglca Forest Directorate (Turkey), Düzce, Turkey: Faculty of Forestry, Düzce University.

Faris, F. \& Fathani, T. F., (2013). A coupled hydrology/slope kinematics model for developing early warning criteria in the Kalitlaga Landslide, Banjarnegara, Indonesia, Progress of Geo-Disaster Mitigation Technology in Asia, doi: 10.1007/978-3642-29107-4_26, 453-467.

Faris F, Wang FW (2014) Investigation of the initiation mechanism of an earthquake- induced landslide during rainfall: A case study of the Tandikat Faris and Wang Geoenvironmental Disasters 2014, 1:12 Page 12 of 13 http://www.geoenvironmental-disasters.com/content /1/1/12 landslide. Geoenvironmental Disaster, West Sumatra, Indonesia, 1(4). doi:10.1186/s40677-0140004-3

Frattii, P., Crosta, G. \& Sosio, R., 2009. Approaches for defining thresholds and return periods for rainfalltriggered shallow landslides. Hydrol, Volume 23, pp. 1444-1460.

Gaurav, K., Saran, S., Stein, A. \& Das, I., 2009. Stochastic Modelling of Land Cover (dynamic) Elements. Thesis ed. Dehradun, India: Indian Institute of Remote Sensing (IIRS) and International Institute for Geoinformation Enschede, The Netherlands.

Guzzetti, F., Dikau, R. \& Glade, T., 2005. Landslide Hazard and Risk Assessment, Bonn: MathematichNaturwissenschaftlichen Fakultät Rheinischen Friedrich-Wilhelms-Univestität Bonn.

Guzzetti, F., Mondini, A. C., Santangelo, M. \& Chang, K. T., 2012. Landslide inventory maps: New tools for an old problem.. Elsevier B. V., I(112), pp. 43-61.

Highland, L. M. \& Bobrowsky, P., 2008. The Landslide Handbook-A Guide to Understanding Landslides. 1st ed. Reston, Virginia: U.S. Department of the Interior \& U.S. Geological Survey.

Huang, J., Ju, N. P., Liao, Y. J. \& Liu, D. D., 2015. Determination of Rainfall thresholds for shallow landslides by a probabilistic and empirical method. Natural Hazards Earth System Sciences, Volume 15, pp. 2715-2721.
Indonesian National Board for Disaster Management, 2016. Badan Nasional Penanggulangan Bencana. [Online]

Available at: dibi.bnpb.go.id

[Accessed 31 September 2016].

Iswar, D. et al., 2010. Stochastic landslide vulnerability modeling in space and time in a part of the northern Himalayas, India. Springer, 178(Environ Monit Assess (2011)), pp. 25-37.

Laprade, W. T., Kirkland, T. E., Nashem, W. D. \& Robertson, C. A., 2000. Seattle landslide study, Seattle: Shannon and Wilson.

Liu, X., 2006. Site-specific Vulnerability Assessment for Debris Flows: Two Case Studies. Journal of Mountain Science, 3(1), p. 21.

Meiliana, N., 2011. Risk Assessment and Landslide Mitigation on Lahat-Pagaralam Street, South Sumatera Province, Yogyakarta: Program Pasca Sarjana Magister Teknik Pengelolaan Bencana Alam UGM.

Nayak, J., Westen, C. V. \& Das, I. C., 2010. Landslide Risk Assessment Along a Major Road Corridor Based On Historical Landslide Inventory and Traffic Analysis, Enchede (Netherland) \& Dehradun (India): The International Institute for Geo-Information Science and Earth Observation (ITC) \& Indian Institute of Remote Sensing (IIRS).

Nicolet, P. et al., 2016. Brief communication: On direct impact probability of landslides on vehicles. Nat. Hazards Earth Syst. Sci., 16(19 April 2016), pp. 9951004.

Northmore, K. J. et al., 2000. Landslide Hazard Mapping : Jamaica Case Study, British Geological Survey: Nottingham.

Nugroho, E. S., Hadmoko, S. D., Kingma, N. \& Van Westen, 2012. Analyzing and Estimating Landslide Risk Impact to Road : a Case Study in Samigaluh District, Kulonprogo Regency, Yogyakarta Province, Yogyakarta \& Twente: Faculty of Geo-information and Earth Science Gadjah Mada University \& University of Twente.

Pierson, L. A. \& van Vickle, R., 1993. Rockfall Hazard Rating System Participants manual, Springfield: National Highway Institute, Federal Highway Administration, US Department of Transportation.

Prina, E., Bonnard, C. \& Vulliet, L., 2004. Vulnerability and Risk Assessment of Mountain Road 
Crossing Landslide. Rivista Italiana di Geotecnica, 2(April), p. 76.

Purnomo, N. H., Sutikno, Sunarto \& Muta'ali, L., 2010. Landslide Risk on Agricultural Land in Kuarter Arjuno Volcano Area, East Java Province, Yogyakarta: Program S3 Geografi Universitas Gadjah Mada.

Salvati, P., Bianchi, C., Rossi, M. \& Guzzetti, F., 2010. Societal landslide and flood risk in Italy. Nat. Hazards Earth Syst. Sci., 10(16 March 2010), pp. 465-466.

USGS, 2017. USGS. [Online] Available at: https://earthquake.usgs.gov/earthquakes/ map/ [Accessed 15 April 2017].
Vennari, C. et al., 2014. Rainfall thresholds for shallow landslide occurrence in Calabria southern Italy (P. Tarolli Edition). Natural Hazards and Earth Sciences, Volume 14, pp. 317-330, 317-322.

Yivru, J., 2015. National Scale Landslide Hazard Assessment along The Road Corridors of DominicaSaint Luca, Enchede, Netherland: Faculty of Geoinformation Science and Earth Observation University of Twente. 